\title{
Habitação em centros históricos: um desafio à integração das políticas públicas
}

\author{
Housing in historic downtowns: a challenge \\ to the integration of public policies
}

Lucia Maria Machado Bógus António Miguel Lopes de Sousa

\begin{abstract}
Resumo
0 artigo parte do suposto de que a habitação, entendida como política pública integrada, constitui um componente central nos processos de reabilitação das áreas centrais das cidades e, principalmente, de seus centros históricos. Propõe estudar, por meio dos exemplos das cidades de Salvador, no Brasil, e do Porto, em Portugal, os condicionantes que permitiram estruturar programas ou políticas públicas continuadas, com significativos resultados nos processos de reabilitação e preservação. Pretende, ainda, contextualizar as formulações programáticas e os fundamentos conceituais a elas associados, de forma a compreender a relevância das práticas de planejamento urbano que integram a questão habitacional, suas formas de articulação e impactos nos processos de sociabilidade e de revitalização funcional dos centros históricos.
\end{abstract}

Palavras-chave: centro histórico; habitação; políticas urbanas; revitalização funcional.

\begin{abstract}
The paper assumes that housing, understood as an integrated public policy, is a key component in the rehabilitation process of the central areas of cities, including their historic downtown. It proposes to study, through the examples of the cities of Salvador, in Brazil, and Porto, in Portugal, the sets of conditions that have enabled to structure ongoing public programs or policies, with significant results in rehabilitation and preservation processes. Furthermore, the paper aims to contextualize programmatic formulations and conceptual foundations associated with them in order to understand the relevance of the urban planning practices that make up the housing issue, their forms of articulation, and impacts on processes of sociability and functional revitalization of historic downtowns.
\end{abstract}

Keywords: historic downtown; housing; urban policies; functional revitalization. 


\section{Introdução}

As consequências da modernidade, conforme as reflexões e críticas de Giddens (2002) e de Bauman (2001), são marcadas por contradições, paradoxos e conflitos, que interferem nos processos de configuração da memória e na construção das representações sobre as cidades, influenciando os modos de olhar, compreender e explicar os processos constitutivos da organização social em sentido amplo ou das vivências urbanas, em sentido mais estrito.

Com efeito, o "pensar a cidade" - entendido nos mecanismos da sua "produção" e nos instrumentos de "planejamento e gestão urbanística" - tem sido objeto de permanente busca de referenciais do processo civilizatório anunciado pela modernidade, cujas consequências tornam-se evidentes na contínua revisão de "princípios", "cartas", "tratados" ou propostas conceituais para um viver moderno.

Um dos objetos dessa contínua revisão de estratégias de "fazer cidade" tem sido os "centros históricos" ou, se quisermos ser mais abrangentes na abordagem analítica, os centros urbanos, enquanto espaços diferenciados nos processos de formação e desenvolvimento das cidades.

Esses espaços centrais, claramente identificados na memória e no discurso dos habitantes da cidade, independentemente do referencial cognitivo e simbólico a eles associado, têm sido objeto de diferenciados entendimentos no âmbito do processo histórico do urbanismo moderno, como têm sido, também, distintos os campos de análise, marcados pela interdisciplinaridade.

Os diferentes entendimentos quanto à importância desses espaços centrais ou quanto a seu significado na constituição e qualificação da entidade "cidade" têm proporcionado vasto conjunto de experiências, contextualizadas quer em uma perspectiva de "reabilitação urbana" - que entende as áreas centrais como potencial indutor de atividades estratégicas (serviços, comércio, cultura ou turismo), segundo processos de adequação espacial e funcional -, quer em uma perspectiva de preservação do patrimônio histórico - que reconhece nos espaços existentes potencialidades indutoras dos mecanismos de construção da identidade social e recuperação das tradições culturais, como fatores de articulação e de coesão da organização sociocultural.

Em muitas dessas práticas experimentadas, tem sido recorrente o princípio de que os grupos sociais instalados, ou seja, a população residente, se não constituem, eles mesmos, o "problema", constituem, no mínimo, um obstáculo decisivo à implementação de determinadas "políticas urbanas".

Nesse sentido, trataremos de compreender como o habitar e a habitação, constituem os elementos fulcrais de sustentabilidade dos centos históricos, considerando o caráter determinante do abrigo e do domínio territorial para a estabilização dos mecanismos de assentamento humano e de estabilização das relações entre os seres humanos e os lugares.

Subentende-se, em muitas das propostas e intervenções, um desajuste programático entre os objetivos anunciados, muitas vezes expressos no discurso dos agentes, e os instrumentos de atuação implementados. Ou seja, em raras circunstâncias, os grupos sociais estabelecidos são considerados, no âmbito das estratégias de planejamento urbano, como elementos indutores dos processos de 
reabilitação, ou revitalização, das áreas centrais das cidades.

Entretanto, outras, e mais raras, experiências entendem como determinante o papel das populações estabelecidas nas áreas centrais, bem como o fomento de ações de ocupação de espaços residenciais abandonados, nos programas de reabilitação urbana. Essas práticas, ainda que sob mecanismos operacionais e métodos diversos, assumiram, como estruturante, a questão habitacional no âmbito das ações programadas de política urbana. A questão habitacional, nessas experiências, não se resume apenas à residência, ao morar, mas ao conjunto de atividades que the estão associadas, como o trabalho, a produção, o comércio e o lazer enfim, o viver.

Entre umas e outras experiências, mais do que as diferenças nos detalhes operativos, observa-se significativa compreensão de "política urbana" e até de entendimento do que é a "cidade".

Por um lado, torna-se explícito o argumento da "mudança" como fator determinante - mudança que, mesmo não sendo explícita, intui-se nos instrumentos de intervenção e que implica, não raramente, o deslocamento dos habitantes em determinados locais da cidade.

Por outro lado, é relevante a preocupação de preservação e qualificação de vivências urbanas instaladas, como fator estruturante do processo de reabilitação funcional e espacial das áreas centrais.

Entre umas e outras experiências decorrem, também, as diferenças, em longo prazo, do impacto das distintas estratégias. Ao contrário das operações de reabilitação urbana pontuais e esporádicas - instituídas de acordo com programas de intervenção localizados, em que os agentes são efêmeros -, as políticas urbanas que se estruturam em ações articuladas assumem a política habitacional - ou seja, a necessidade de manutenção de uma massa de residentes em situação estável - como um elemento fundamental para sustentação dos mecanismos de reabilitação urbana. Assume-se aí a importância da preservação das estruturas identitárias, bem como da construção de representações simbólicas reconhecidas e assimiladas por um conjunto bem determinado de grupos sociais que possam legitimar, por exemplo, as ações de preservação patrimonial e/ou as manifestações culturais coletivas.

Assim, o presente artigo entende que a habitação, como política pública integrada, constitui um componente determinante para os processos de reabilitação das áreas centrais das cidades, especialmente dos centros históricos.

Pretende, assim, analisar, tomando como exemplos dois casos emblemáticos de intervenção em centros históricos, notadamente, as cidades de Salvador, no Brasil, e do Porto, em Portugal, os conjuntos de condicionantes que, em diversas experiências, permitiram estruturar programas ou políticas públicas continuadas, com significativos resultados nos processos de reabilitação e preservação dos centros históricos.

Importa, ainda, contextualizar não apenas as formulações programáticas, mas, também, os fundamentos conceituais que thes estão associados, de modo a compreender, em um sentido mais amplo, a relevância das práticas de planejamento urbano que integram a questão habitacional e a verificar as formas de articulação e os respectivos resultados nos processos de sociabilidade e revitalização funcional dos centros históricos. 
Desse modo, pela análise e avaliação documental e pela verificação local de um conjunto de experiências inovadoras que precederam a configuração de políticas de habitação para os centros históricos nas duas cidades consideradas, pretende-se apontar as transformações ou os desenvolvimentos conceituais dos quais resultaram significativas contribuições para a formulação de políticas urbanas que enfrentaram as carências habitacionais, sintomáticas das áreas centrais.

Além disso, como evidência do oposto, importa também verificar as circunstâncias em que não têm ocorrido as referidas práticas e onde o processo histórico evidencia o desajuste ou a não concretização dos pressupostos programáticos.

Ainda que se baseando em informações empíricas pouco mensuradas, pretende-se sustentar essa proposta analítica com base no conhecimento dos diversos instrumentos, projetos e análises oriundos de várias áreas do conhecimento, como a sociologia, a antropologia e a geografia, de forma a configurar um quadro de referência operativo que contribua para uma eventual construção de programas de intervenção em centros históricos.

Mesmo não sendo o objetivo da discussão a proposição de políticas de habitação para os centos históricos, importa estabelecer, com base na análise das experiências, alguns caminhos de formulação metodológica que permitam, de algum modo, configurar processos de análise dos impactos das ações implementadas e que integrem, pelo menos como componente de avaliação, a questão habitacional.

Os questionamentos determinantes que envolvem a questão que se pretende sustentar se relacionam, especialmente, com ideia de que a produção do espaço urbano agrega dimensões estruturantes que não se resumem ao domínio espacial, do qual a arquitetura e o urbanismo se apropriaram, muitas vezes, enquanto monopólio de conhecimento, nem apenas ao domínio econômico, como muitas teorias associadas ao "desenvolvimento" e ao "progresso" têm enfatizado.

A abordagem dialética dos fenômenos urbanos, no caminho iniciado por Hegel e Marx para a explicação da natureza contraditória das relações sociais e da relação entre indivíduo, natureza e sociedade, foi largamente desenvolvida por Quijano, Castells, Lefebvre, Lojkine, Gottdiener e Harvey, entre outros que trouxeram, para compreensão e explicação das questões urbanas, uma complexidade metodológica e de referenciais analíticos que permitiram alargar e diversificar o olhar sobre a cidade.

A noção de "produção social do espaço", na acepção desenvolvida por Lefebvre, por exemplo, agrega ao "espaço concebido" aquele que o planejamento urbanístico prima por se apropriar - o "espaço vivido" e o "espaço percebido". Essa recolocação metodológica, fruto de uma aproximação analítica ao processo histórico de "fazer cidade", induz à noção de que o espaço contém e está contido, nas relações sociais, e, por inerência, a sua produção associa-se aos mecanismos da reprodução social, que, em si, contêm estruturas de múltipla dependência e influência que incluem as dimensões econômica, política e cultural.

No âmbito dessa abordagem dialética da produção do espaço, este não se constitui como um produto dessas relações, e inter-relações, mas antes como um processo - de apropriação e construção, individual e coletiva - que não se esgota em momentos determinados como uma 
construção, mas que se constitui, no cotidiano, como um direito que se conquista - o "direito à cidade" - nas palavras de Lefebvre.

É no contexto dessa estrutura metodológica, de análise dos fenômenos e dos fatos urbanos, que nos propomos entender a relação "habitação" e "centros históricos", não apenas no sentido da incorporação de mais uma dimensão analítica ou programática que se soma de forma avulsa, mas como uma circunstância unitária enquanto processo de produção do espaço - a produção social do espaço.

\section{Da produção e reprodução da cidade; a sociedade urbana e o urbanismo}

Quantas vezes se afirmou, e se escreveu, que muitas são as cidades que se pode encontrar em uma cidade?

Essa paradoxal justaposição de tempos e espaços, de vivências em diferentes temporalidades no mesmo lugar e de distintos espaços num mesmo momento é motivo para que se questione: como nos posicionarmos para viver, ao mesmo tempo, a cidade real e a cidade imaginada? Ainda que todas as cidades, historicamente, apresentem uma tensão entre o visível e o invisível, entre o que se sabe e o que se suspeita ou conjectura, o que mudou com a cidade contemporânea é a complexidade das experiências que permitem responder àquela pergunta.

Diversas formas de imaginar as cidades - desde a literatura até o cinema e a música - permitem, mesmo, transgredir os estereótipos e as narrativas e responder, de forma criativa e estética, às cidades que se desenharam e produziram, sob o manto do capitalismo tardio: homogêneas, diferentes, indiferentes, sem identidade.

Perante essas cidades, brotam as figuras de cidades outras: que se reclamam nômades, ambíguas, ambivalentes, com espaços heterogêneos, mutantes e fraturados, rompidos e esgarçados.

Existe uma oscilação de imagens, de conteúdo, ou de substância, entre o legado visível e invisível, expressa na tensão entre a cidade experimentada fisicamente e a cidade imaginada em narrativas ficcionadas: aquelas descritas em Yoknapatawpha, de William Faulkner; Comala, de Juan Rulfo; Santa Maria, de Juan Carlos Onetti; ou Macondo, de Gabriel García Márquez.

As cidades contemporâneas contêm, e geram, os signos da falência da modernidade e do capitalismo industrial - fragmentos das antigas fábricas, pedaços de comércio decadente, complexos habitacionais operários e de classe média degradados, escolas e hospitais públicos dilapidados -, ocultos pela presença e domínio do pós-moderno sofisticado e pelo asséptico aço, vidro espelhado e viadutos estaiados, que renovam outra nova promessa, sem discursos eloquentes, mas com imagens irresistíveis no apelo ao imaginário, ao novo.

Considerando, na acepção de Lefebvre (2001), que o indivíduo usa o espaço para viver de acordo com as condições naturais e históricas específicas, tal circunstância exige definições mais exatas dos níveis de análise, os quais não devem separar-se nem confundir-se, mas agregar-se à reflexão. Segundo o autor, é possível seguir dois procedimentos, tanto do geral para o específico, quanto partindo do 
singular para alcançar o geral, recorrendo a informações e significações do observável nas singularidades. 0 segundo caminho reúne teoria e prática, apropriando-se das alteridades e das representações.

0 termo "direito à cidade", independentemente do sentido conceitual e dialógico atribuído por Lefebvre, transforma-se na chave para grande parte das propostas de revisão das metodologias de análise da cidade, bem como das experiências de planejamento e gestão urbana. Trata-se de um despertar para as possibilidades que a cidade, como produção social, contém de potencial de manifestação e exercício da cidadania, considerada em ampla acepção: não só de expressão de direitos individuais e coletivos, mas de criação, produção, participação e transformação da realidade.

Ainda que com dificuldades de apropriação por parte do "urbanismo", aquele movimento que reivindica o direito à cidade, vê-se obrigado a estabelecer, não apenas outro olhar, mas nova plataforma ou ponto de partida, para a questão urbana. 0 que distingue, então, essa abertura da cidade aos seus usuários, com eventos que apelam à livre expressão de práticas e desejos e ao "direito à cidade" de Lefebvre?

As proposições de Lefebvre não se dirigem à cidade formal, mas ao espaço social no âmbito da formulação filosófica que entende a totalidade dos indivíduos, ou o homem total. Enquanto os eventos urbanos são, correntemente, compreendidos no campo dos sistemas - científicos, técnicos, teóricos, práticos, políticos -, persistem, para além destes, resíduos que não são reconhecidos pelos sistemas, mas que possuem as faculdades de permanência e resistência, interferindo de forma relevante quando os sistemas os pretendem "integrar", ou seja, dissolvê-los.

Nessa reflexão, que fundamenta este trabalho, destacam-se dois campos de análise centrais, sem, no entanto, fragmentar e isolar a análise dos processos que compõem o núcleo de discussão em torno do "direito à cidade": os centos urbanos, ou, mais especificamente, os centros históricos, e a habitação. Trata-se, não de temas ou pedaços da cidade, mas do cerne das práticas cotidianas que formam o lastro de consolidação das cidades e lhe atribuem o caráter de permanência.

Não por acaso, as representações e o imaginário sobre a cidade passam pelo seu centro, independentemente da sua atualidade funcional, da sua qualidade ambiental e, até, da sua efetiva ocupação. Como, também, a "identidade" dos seus moradores passa pelo "bairro" onde residem, ainda que lá não possam ocorrer a sua rotina diária, as suas atividades laborais ou lúdicas. Existem, portanto, valores associados a essas categorias socioespaciais que superam o mero caráter do lugar geográfico ou da acepção funcionalista do habitar. Trata-se da construção de significados que compõem as representações e os referenciais coletivos e individuais, aglutinando o sentido público e privado do viver, assumindo um papel integrador, unânime, quase inquestionável.

\section{Habitação e centro histórico: morar e habitar em Salvador e Porto}

0 "patrimônio" que frequentemente se associa, também, aos centros históricos e que se 
vulgariza na ideia de que os centros históricos são, essencialmente, patrimônio, vê-se frequentemente destituído da dimensão social concreta, do cotidiano, relacionando-se com ele, muitas vezes, de forma conflituosa. Não raramente, atribui-se a certo uso social da cidade o desvirtuamento do patrimônio, acusando-se os moradores de não respeitar, não preservar e não conservar aqueles símbolos da memória e da identidade coletiva. Entretanto, são aqueles poucos moradores, senão os agentes de sustentação daqueles modos de vida de que se fala, pelo menos os resistentes sobreviventes dos processos de desestruturação e transformação dos centros.

Assim, aparentemente, é entre imaginários e representações que se formula grande parte dos discursos, estejam eles orientados para uma perspectiva mais social, que se refere a hábitos, usos, costumes, tradições e modos de vida, ou mais espacial, enaltecendo qualidades estéticas, paisagísticas, morfológicas, construtivas e históricas dos edifícios e dos tecidos urbanos.

Nessa perspectiva, o retorno aos centros das cidades comporta uma dimensão alienante da questão urbana. Por um lado, introduz uma fratura territorial, muitas vezes geográfi$\mathrm{ca}$, isolando o centro e separando-o da cidade; e, por outro lado, faz esquecer a cidade, a sua construção, retendo um tempo, passado, ainda que se desconheça a sua verdadeira dimensão, resumindo-a "àquela" cidade e transformando a "outra" em espaço amorfo do ponto de vista da geração de valores e significados.

Com efeito, misturando-se na narrativa a cidade e o patrimônio, não que isso seja uma impossibilidade, mas formulando-se uma figura retórica de síntese denominada "centro histórico", abre-se espaço para o surgimento de equívocos conceituais que redundam em contradições na prática cotidiana.

Por um lado, o termo "centro histórico" aparece codificado por vários campos do conhecimento - arquitetura, urbanismo, história, geografia, sociologia, antropologia, etnografia -, que tendem a conotá-lo, de forma abrangente, com o termo patrimônio. Por outro lado, essa generalização conduz mais à representação de alguma coisa do que à coisa, pois nem sempre esses "centros" são centros históricos enquanto lugares simbólicos.

Se o discurso preponderante é o "retorno ao centro", como também já existiu o "retorno à cidade" no passado recente, os mecanismos de construção da narrativa permanecem idênticos: a necessidade de realimentar 0 apelo à cidade, formando marcos referenciais, ilusórios ou não, fortalecendo os processos de dominação pela manipulação dos símbolos e dos valores em torno de interesses econômicos e políticos concretos. Se, há poucos anos, a imagem da tecnologia, da inovação, da especialização de serviços compunha a competição entre as cidades globais, atraindo e fazendo movimentar o capital global, os centros históricos configuram hoje um nicho, ora complementar, ora concorrente, nesse renovado combate pela hegemonia dos negócios, que sempre se referencia às cidades. 0 turismo encontra, nesse espaço urbano, especificidades que só as cidades "tradicionais" - ditas históricas - conservam e que já não se restringem aos monumentos, formatando um ambiente, ou uma vivência, que agrega atributos históricos, gastronômicos, tradições, usos e costumes pitorescos, além de outros eventos designados como "culturais". 
Instituir uma dinâmica de produção e reprodução do espaço urbano em um tecido que já não reunia condições para acolher as atividades econômicas e produtivas dominantes (e, por isso, tinha sido paulatinamente abandonado) constituía o grande desafio para a sustentabilidade dos centros históricos. Enquanto o restante da cidade é movido por mecanismos de reprodução do capital, e as relações sociais orientam-se em torno da satisfação das necessidades materiais baseadas no valor de troca, uma parte da cidade parece querer persistir em sobreviver em função do valor de uso fundado em suposto quadro socioespacial. Essa oposição de tendências gera desequilíbrios entre a cidade dita autossustentável, de acordo com as regras e dinâmicas dos "mercados", e a cidade que ainda, ou já, não possui os atributos necessários para participar da mesma lógica da produção urbana.

Parece, assim, mais compreensível falar de patrimônio histórico suportado pelas experiências que ocorrem no campo simbólico e das representações sociais, amplamente reconhecidas pelo grupo social, às quais se adere de forma qualificada, com conhecimento e apropriação dos valores, identificando as possibilidades de construção da memória e da identidade.

Embora se vislumbrem diversos caminhos para a revisão conceitual do patrimônio histórico, sobretudo no desenho da política do patrimônio, a sua discussão fundada em outras possibilidades de gestão pode ser identificada no âmbito das experiências urbanísticas dos anos de 1970 e 1980. Os modelos de "reabilitação urbana", então também denominados "requalificação urbana", traziam como proposta, não apenas a releitura do urbano a partir dos interesses e conflitos instalados e da compreensão dinâmica e interdisciplinar dos processos socioespaciais, mas, também, a inclusão da "cidade" na cidade, em face da fragmentação e da segregação que esta apresentava.

Poucas experiências em grandes intervenções urbanas foram além de abordagens temáticas, embora afetassem áreas extensas das cidades e com repercussões estruturais relevantes. 0 patrimônio histórico, ou os centros históricos, constituíram, nesse contexto, também um tema isolado, ou, de forma perversa, o pretexto, ou a imagem de propaganda, para abrigar, no seu entorno, outras intervenções que se mostraram inconsequentes no processo de qualificação do urbano. Ao ponto de os impactos mais visíveis se verificarem em um processo de reprodução de modelos formais, e até econômicos, por diversas cidades do mundo, em vez de gerarem, localmente, experiências de extensão de programas ou de renovação dos modos de fazer cidade.

Um dos elementos-chave para a compreensão da inconsistência dessas intervenções de reabilitação urbana em áreas centrais é, precisamente, a habitação.

Não se trata de ausência do tema na equação da estratégia nem, tampouco, de carência de estudos estatísticos, de dados socioeconômicos da população, de caracterização da situação habitacional desses lugares. Entendemos que se trata de ausência de entendimento sobre o que significa o "habitar". Em muitos dos posicionamentos sobre a preservação dos centros históricos, mesmo os mais recentes, a participação social, como fator decisivo no fomento e consolidação dos valores simbólicos e de uso, é entendida como relação externa aos objetos, considerando apenas a dimensão pública como campo das práticas de sustentação 
da memória e da identidade. A habitação apresenta-se, naquelas circunstâncias, apenas como função urbana e, raramente, como dimensão da existência dos indivíduos.

Tal acepção emerge, paradoxalmente, nos fenômenos de gentrification decorrentes das grandes intervenções urbanas, onde a valorização dos recursos locais - simbólicos, culturais, monumentais, artísticos, entre outros -, por via da especulação turística e imobiliária, inviabiliza a permanência de alguns grupos sociais de baixa renda e suas respectivas atividades, embora esses empreendimentos urbanos contenham uma vertente habitacional e considerem ações e mecanismos de participação social, mas que se apresentam, desde o início, desvirtuados.

Os centros históricos, como representações amplas do patrimônio, requerem que os seus habitantes, para além de moradores, também ali "vivam", ali constituam "lar", no sentido de efetivar a produção do espaço e, enfim, o direito à cidade.

Os elos na cadeia dos processos de produção do espaço foram, como já observamos, fragilizados com a mudança do valor de uso dos espaços para o valor de troca ou por sua construção a partir da lógica do mercado, fragmentando, e por vezes dissolvendo, os mecanismos de relação entre os sujeitos, individuais e coletivos, remetendo-os a processos de produção isolados, autonomizados e localizados no território, impedindo sua leitura e apropriação como totalidade.

Não se trata, no entanto, de ausência de conceitos, modelos e experiências. Desde o século XVIII, as transformações urbanas, e as respectivas propostas e projetos urbanísticos, tinham no "habitar" um foco referencial estruturante. Todavia, registra-se a formulação de modelos que tendem a aproximar-se da ideia de hábitat, enquanto complexo ambiental da vida humana, onde se consolidam princípios e formas de "viver", considerando fatores de equilíbrio e sustentabilidade do meio ambiente, na sua articulação com o desenvolvimento das atividades humanas.

Nessa perspectiva, o "habitar" era componente importante do cotidiano e compunha o ciclo das atividades de trabalho, de lazer e das outras práticas de vida coletiva. A composição do lugar de "habitar" - o alojamento, a habitação, no modelo de viver burguês - não era apenas determinada pelas atividades privadas, mas concentrava muitas das práticas que definiam certo conceito civilizacional - os comportamentos, os mecanismos de relação familiar, os hábitos e os costumes e, mesmo, as formas de sociabilidade, considerando que, em determinados momentos e para alguns grupos sociais, a habitação era uma extensão da vida pública.

Na Paris de Haussman, na Barcelona de Cerdá, na cidade-jardim inglesa, na ville radieuse de Corbusier ou na Brasília de Lúcio Costa, a habitação constitui não apenas a massa edificada da cidade, como, também, corresponde à proposta de hábitat e determina a forma urbana marcando a linguagem arquitetônica. No entanto, apesar de o projeto pressupor modelos de indivíduos, grupos e classes e seu respectivo comportamento, no tempo, prevaleceu o anonimato dessa massa de sujeitos, quase se desconhecendo a sua efetiva relação com as habitações então projetadas e construídas.

Instala-se, assim, um paradoxo: ao mesmo tempo que o planejamento da cidade tende a configurar conceitualmente modelos de 
hábitat que determinam formas precisas de organização social e da atividade humana, definindo minuciosamente tipos e padrões - de trabalho, de mobilidade, de lazer, de cultura -, constata-se a desmobilização dos indivíduos na formulação e realização desses processos. Ao mesmo tempo que o "projeto" parece inserir os indivíduos em uma totalidade provida de ordem e sentido, dando significado ao seu "ser no mundo", relacionando-os por meio de mecanismos de sociabilidade com outros indivíduos e com as instituições inseridas nos mesmos processos, aparentemente os destituiu da oportunidade de "criarem" o seu "lugar".

Entendemos que estamos em face de contextos em que as transformações inscritas na cidade moderna capitalista alteraram também os sujeitos e, assim, as possibilidades de operar mecanismos de sociabilidade, de relação com os lugares, de pertencimento e de identidade.

Um dos elementos centrais dessa mudança é a habitação. A perda de "competências" pelo núcleo familiar, estrito ou alargado, enfraqueceu não apenas as relações que se desdobravam a partir das atividades exercidas pelos seus membros, mas o significado do lugar edificado, entendido como o centro do espaço do habitar, a casa.

A redução do âmbito de influência da casa, antes composto por conjunto de atividades e relações sociais em torno de um campo espacial, mais ou menos amplo, centrado na edificação que abrigava a família, ao mero "morar" em uma construção localizada em certo bairro da cidade, extinguiu o espaço social das articulações funcionais, simbólicas e afetivas que caracterizavam determinados, e diversificados, modos de viver na cidade.
A recomposição dessas relações, subjacente em muitos dos discursos dos "projetos urbanos", que tem por objetivo "revitalizar" tornar a "dar vida" à cidade -, não considera, frequentemente, a dimensão e a extensão das relações que importa "restabelecer". Entendemos que sem envolver a habitação, como prática urbana de sustentação do "estar" e do "permanecer", perdem substância e sentido algumas expressões como "participação social", "apropriação", "ressignificação do espaço público" e outras que formam o léxico do urbanismo e da gestão urbana contemporânea.

Poderá parecer paradoxal invocar, hoje, a habitação como requisito decisivo para "resolver" a cidade, quando o projeto modernista tinha, aparentemente, nas unidades residenciais, o elemento estruturante de certo "viver" moderno, do novo habitat.

Todavia, não se avaliou, pelo menos no campo do conhecimento do urbanismo, o impacto do viver moderno sobre a organização das relações sociais. Essa desvinculação, ditada pela produção dos novos modos de produção, entre os consumidores dos bens e os seus produtores, conduz, por indução do "espírito" de mercado, à coisificação dos espaços construídos: do mesmo modo que automóvel é uma "coisa" que serve à mobilidade, a "casa" serve para morar, o parque serve para brincar, a igreja para rezar. Os artefatos urbanos encontram-se, então, desencarnados da cultura, desvinculados dos sujeitos individuais e coletivos e tendem a ser destituídos de referência simbólica no âmbito do conjunto.

Assim, quando, antes, referimo-nos ao potencial equívoco que poderá estar presente no discurso que acompanha muitas das recentes experiência e projetos de "revitalização" 
urbana, pretendemos explicitar algumas incongruências que podem decorrer da imprecisa leitura do processo histórico. Frequentemente, as propostas e os projetos apoiam-se em "soluções" prontas e dadas, como "coisas" facilitadoras ou dinamizadoras de práticas coletivas, considerando a faceta da vida pública dos indivíduos. 0 "envolvimento" social, uma espécie de apelo à participação da sociedade, dá-se pela oferta, ainda que se reconheça a existência de potencial procura, e, raramente, pela produção, pela criação, gerada pelos sujeitos.

As experiências de restabelecimento do uso do espaço público com atividades qualificadas não têm implicado, necessariamente, a reconstituição de práticas, de códigos, de condutas, que se pressupõem naturais aos sujeitos, como se a "tradição" e a "memória" se perpetuassem sem a experiência concreta.

Nem nas casas dos centros históricos das cidades se realiza um viver antigo, aristocrata, burguês ou das classes dos mestres de ofícios e comerciantes; nem nas unidades residenciais modernistas se cumpre o padrão funcionalista; em ambas, persistem tentativas de concretizar um imaginário, por vezes contraditório com as características daqueles espaços concebidos, mas buscando, apesar dos conflitos, estabilizar as referências que determinam certa centralidade daqueles lugares: o ponto de onde se parte e, em algum momento da rotina, se retorna, e, em alguns casos, o lugar de onde já não se sai.

Aquele poderia ser o retrato do denominado centro histórico da cidade do Porto em 1974, momento em que ocorre a Revolução dos Cravos. A Ribeira, o Barredo e a Sé, os bairros que formam o núcleo de formação da cidade, apresentavam-se naquele momento como o tecido mais degradado da cidade, mas que possuía uma elevada densidade de ocupação dos imóveis que poderiam ser ainda habitados, onde se amontoavam famílias inteiras de baixa renda e de desempregados. Tal circunstância decorria de prolongado enfraquecimento da estrutura produtiva que sustentou a cidade desde o final do século XIX - a indústria - e que se acentuou nas últimas duas décadas da ditadura.

0 slogan popular dos primeiros dias da revolução - "casas sim, barracas não" - retrata com clareza a situação do alojamento na cidade do Porto. Não se tratava de carência de unidades, mas de carência de "dignidade" nas condições das habitações. A cidade antiga, ainda não denominada histórica, denotava aquelas características contraditórias: um parque habitacional que, pelo seu estado de conservação e paulatino abandono, já não correspondia a requisitos de habitabilidade condigna, e uma população residente, que sem alternativas se mantinha refém daquela condição. Inicialmente o Saal - Serviço Ambulatório de Apoio Local - e, posteriormente, o Cruarb - Comissariado de Renovação Urbana da Área da Ribeira/Barredo - estabeleceram uma abordagem, em conjunto com as associações de moradores formadas para esse fim e com os proprietários dos imóveis, a qual buscava a conservação do patrimônio e dos bens culturais, a renovação do ambiente urbano da área, a reinserção da população residente, a consolidação e desenvolvimento do turismo, a expansão e renovação da atividade comercial e a implementação de uma rede de parcerias de agentes sociais. A sustentação do realojamento das populações nos imóveis reabilitados dava-se em regime de aluguel apoiado pelo 
município e previdência social, buscando fixar o maior número de famílias nas antigas áreas de residência, ao mesmo tempo que permitia garantir aos proprietários as rendas adequadas à manutenção daquele patrimônio.

Se aquele processo se estabeleceu sob a influência dos programas socialistas, que formaram a maior parte dos executivos municipais desde a revolução de 1974, com a chegada da gestão municipal neoliberal de 2001 a 2013, assistiu-se ao desmantelamento da política habitacional, não só para o centro histórico como para a restante da cidade do Porto. 0 argumento assentava no fato de não existir retorno dos investimentos públicos, e, portanto, o "mercado" deveria encontrar os mecanismos adequados à sustentabilidade, tendo como mecanismo de fomento os investimentos em equipamentos e no espaço público como motores para a geração de incentivos às atividades relacionadas à exploração dos negócios do turismo - lojas de artesanato e de recordações, restaurantes, bares, salas de exposições.

Apesar do progressivo abandono das populações residentes - porque deixaram de ter apoio no aluguel social e porque o estado de conservação dos imóveis piorava com a ausência de manutenção pelos proprietários e pelo município -, os poucos que permaneceram não dificultaram a possibilidade de intervenção em larga escala pelos agentes imobiliários a ponto de inviabilizar a atuação pontual, edifício a edifício, que pudesse gerar um cenário de mudança apelativo à reocupação do centro histórico por outro "tipo" de moradores.

Mas o impasse e a desmobilização do setor imobiliário e também o baixo investimento público conduziram a um cenário de cerca de $75 \%$ dos imóveis em mau estado de conservação, alguns deles incapazes de acoIher qualquer uso, levando a gestão municipal a reconhecer o fracasso dos mecanismos de mercado na produção e sustentação do espaço urbano. Em 2003, foi criada pelo município a Sociedade de Reabilitação Urbana de capitais públicos - Porto Vivo - que visava instituir mecanismos de financiamento com a participação de fundos privados de investimento no sentido de configurar atuação em larga escala e, ao mesmo tempo, formatar abordagens mais integradas à questão da reabilitação urbana, considerando os problemas de propriedade, de reinserção de populações, de instalação de serviços públicos, sociais e educacionais, de fomento ao comércio local e de diversificação de usos e de utilizadores.

Não sendo perceptível, hoje, o "repovoamento" expressivo do centro, é notória a reversão do quadro do estado de conservação dos imóveis em setores específicos, anunciando-se que só menos de $50 \%$ destes se encontram em mau estado de conservação, sendo constatável a reformulação de mecanismos de sociabilidade entre os diversos sujeitos sociais individuais e coletivos - que permitem mediar interesses e potenciais conflitos. Reconhece-se também, ainda que esporadicamente, a reapropriação pela população da cidade, bem como pelos residentes, do seu centro histórico. Entende-se que a mudança está sendo operada, precisamente, pela reintrodução do tema da habitação nas estratégias de intervenção, embora não sejam ainda claros os mecanismos da política pública que irão compensar os desequilíbrios da capacidade financeira dos potenciais moradores, nem garantir, em médio prazo, a viabilidade de conservação dos imóveis hoje restaurados. Entretanto, o debate instalado traz 
a questão habitacional como desafio à reconstituição da política habitacional, estimulando a realização de estudos que contemplem diversificadas modalidades de ação, tendo em vista integrar mecanismos de financiamento com programas sociais complementares, levando em conta a estruturação das práticas culturais da cidade.

Se é possível identificar nos processos de intervenção no centro histórico da cidade do Porto um ciclo, que se inicia com a efetiva participação da população do centro histórico na formulação dos programas e projetos de intervenção que agregavam a questão da habitação à reabilitação dos imóveis, para além do modelo da cidade turística monofuncional, típico das cidades históricas globais - retoma-se , hoje, a questão da habitação como fator decisivo de sustentabilidade não só do centro, mas de todo o tecido urbano.

Na cidade de Salvador, por contraste, registra-se o ciclo oposto, com impactos também diversos. A intervenção mais estruturada no centro histórico de Salvador, no Brasil, inicia-se em 1992, tendo como foco das ações a área do Pelourinho e tendo como gestores a Conder - Companhia de Desenvolvimento Urbano do Estado da Bahia - e a Sedur - Secretaria de Desenvolvimento Urbano do município de Salvador. Tratava-se de um Programa que visava fundamentalmente à criação de um polo de atividade turística, do qual decorria ampla e sistemática intervenção no edificado existente que se encontrava, à época, em mau estado de conservação, alojando grupos sociais de baixa renda.

A estratégia adotada - que passava pela desocupação integral dos imóveis por setores e por etapas, sua restauração e adequação a novos usos - viu-se claramente definida quando apresentou aos moradores as alternativas de serem indenizados e realojados provisoriamente em outro local ou realocados em imóvel recuperado, mediante novo contrato de aluguel. A aparente sedução da indenização para indivíduos de baixa renda e a forma autoritária como o poder público lidou com as desocupações resultaram no abandono do local, por parte de residentes, e o residual retorno de alguns após as intervenções. A questão habitacional não fazia parte da equação do Programa de Reabilitação do Centro, e as unidades residenciais disponíveis após a intervenção entraram no circuito do mercado imobiliário, procedendo-se, assim, à renovação do tecido social do centro histórico. Nesse contexto, a maioria dos novos moradores, comerciantes e outros residentes não possuía com aquele espaço qualquer vínculo em relação a vivências anteriores, nem participou de forma ativa no processo.

O Programa de Recuperação do Centro Histórico de Salvador não sofreu, ao longo das suas seis primeiras etapas, mudanças significativas na estratégia de atuação e só em 2002, já na vigência do Programa Monumenta, do Ministério da Cultura, estabeleceu-se, na denominada sétima etapa, a reavaliação dos processos e instrumentos de atuação, fruto da constituição de movimento de moradores e da ação do Ministério Público que, entretanto, acusava o governo do Estado da Bahia de promover a "assepsia social" fomentando a expulsão das famílias residentes.

Assim, a sétima etapa, por meio da criação de um Comitê Gestor, revestia-se da intenção de mediar interesses, reverter métodos de intervenção urbana e, fundamentalmente, propiciar condições de permanência às 
populações residentes, tendo como referência a manutenção dos agrupamentos familiares. Nesse sentido, foi definida estratégia de remanejamento e alojamento provisório durante as intervenções de reabilitação dos imóveis, ao mesmo tempo que se estruturavam esquemas de financiamento, mais ou menos subsidiados, que permitissem às famílias obter o equilíbrio financeiro adequado ao investimento nas obras de intervenção. Também foram desenhadas articulações com outras fontes de recursos que prometessem sustentar a geração de renda a partir de atividades produtivas e comerciais instaladas nos respectivos imóveis, bem como a instalação de serviços comunitários de apoio e requalificação do espaço público.

A sétima etapa, à qual não se seguiu qualquer outra, permitiu, ainda que com dificuldades operacionais e de mediação entre os interesses do governo do Estado, dos promotores imobiliários e dos moradores, instituir dinâmica de participação que implicou considerar uma estratégia para a questão habitacional, ainda que não se possa deduzir dela uma política de habitação. No entanto, o processo reverteu $a$, aparentemente inevitável, perda de apropriação dos mecanismos de produção da cidade e a perda dos mecanismos de construção das representações coletivas e da identidade do lugar.

0 abandono do Programa, desde 2010, por parte do governo do Estado e do Município, bem como o encerramento do Programa Monumenta, com a decorrente indefinição de entendimentos sobre a intervenção no centro histórico da cidade de Salvador e a consequente ausência de consolidação de iniciativas e investimentos já realizados, indicam, provavelmente, o fim de um ciclo de qualificação dos processos de produção da cidade , que se vê refletido em cenário de abandono de imóveis e no baixo índice de reocupação do centro.

\section{Conclusões}

Como principal motivação para o presente artigo, apresentou-se a circunstância de que 0 "pensar a cidade" - entendido nos mecanismos da sua "produção" ou nos instrumentos de "planejamento e gestão urbanística" - tem sido objeto de permanente busca de referenciais do processo civilizatório anunciado pela modernidade, cujas consequências tornam-se evidentes na contínua revisão de "princípios", "cartas", "tratados" ou propostas conceituais para um viver moderno.

Pode parecer paradoxal invocar, hoje, a habitação como requisito decisivo para "resolver" a cidade, quando o projeto modernista tinha, aparentemente, nas unidades residenciais, o elemento estruturante de certo "viver" moderno, do novo habitat.

Todavia, não se avaliou, pelo menos no campo do conhecimento do urbanismo, o impacto do viver moderno sobre a organização das relações sociais. Essa desvinculação, ditada pela produção dos novos modos de produção, entre os consumidores dos bens e os seus produtores, conduz, por indução do "espírito" de mercado, à reificação dos espaços construídos. Os artefatos urbanos encontram-se, então, desvinculados da cultura, dos sujeitos individuais e coletivos, e tendem a ser destituídos de referência simbólica no âmbito do conjunto.

Nesse contexto, a valorização dessas produções e o seu sentido nas representações sociais desses espaços têm como base 0 
"estranhamento", ou a novidade, e não a identidade. 0 reconhecimento dos valores, que não está desligado das estratégias de produção das "coisas" - artefatos e espaços urbanos -, envolve sujeitos, instituições e práticas em torno do mercado; o valor de troca, que agrega os símbolos e o imaginário social na mesma formulação, ou ordem ideológica.

Em todos esses "cenários", independentemente da categorização dos lugares - espaços centrais ou centos históricos -, tem prevalecido a ideia de que se trata de espaços que requerem uma abordagem diferenciada. Eles têm se constituído, sempre, como um "problema", no qual se condensam muitos conflitos de interesses e, sobretudo, muitas das contradições no âmbito dos processos sociais da apropriação e uso deles mesmos.

A partir da leitura dos processos de intervenção nos centros históricos das cidades de Salvador e do Porto, verificou-se que tem sido recorrente o princípio de que os grupos sociais instalados (a população residente), se não se constituem o "problema", constituem, no mínimo, um obstáculo importante à implementação de determinadas "políticas urbanas". Em muitas das propostas e intervenções, existe um desajuste programático entre os objetivos anunciados, muitas vezes expressos no discurso dos agentes, e os instrumentos de atuação implementados. Ou seja, em raras circunstâncias, os grupos sociais estabelecidos são considerados, no âmbito das estratégias de planejamento urbano, como indutores dos processos de reabilitação ou revitalização das áreas centrais das cidades.

As experiências de restabelecimento do uso do espaço público com atividades qualificadas não têm implicado, necessariamente, a reconstituição de práticas, de códigos, de condutas, que se pressupõem naturais aos sujeitos, como se a "tradição" e a "memória" se perpetuassem sem a experiência concreta.

A habitação, enquanto espaço de permanência e não apenas de moradia, instiga ao "habitar"; poderá ser compreendida na escala da produção e do viver a cidade e costurar as práticas dispersas que hoje se fomentam para a dinamização - revitalização ou humanização - do espaço e vida pública e das representações coletivas.

Tal como se pode constatar no estudo dos centros históricos das cidades de Salvador e do Porto, a habitação não deverá ser tomada somente pela sua vertente de fixação de residentes, assumindo, nessas circunstâncias, o caráter de programa de moradia, mas deve alcançar o patamar de política urbana para que os sujeitos sociais e institucionais integrem um âmbito alargado de ações, das quais participam, não como protagonistas esporádicos, mas como cidadãos e agentes de cidadania em uma perspectiva universalista de direitos,

Entende-se, por fim, que o que a habitação traz de relevante para os centros históricos, enquanto habitar, e não apenas como uso entre as funções da cidade ou como mercadoria valorizável no processo imobiliário especulativo é, precisamente, a permanência de pessoas, a continuidade ou a constituição de cotidianos e, assim, a possibilidade de formar as representações coletivas, instituir valores e ressignificar memórias. Ao mesmo tempo, a reutilização dos imóveis dos centros históricos, habitando-os e atualizando-os na sua capacidade de uso, qualifica a habitação, inserindo-a em um habitar, em um lugar espacialmente qualificado que carrega memórias 
que instigam à construção de mecanismos de pertencimento e sociabilidade, fortalecendo as identidades, a autoestima e a apropriação do processo histórico; dando-lhe prosseguimento, não como mera transmissão, mas como transformação da realidade urbana.

\section{Lucia Maria Machado Bógus}

Pontifícia Universidade Católica de São Paulo, Faculdade de Ciências Sociais, Programa de Estudos Pós-Graduados em Ciências Sociais. São Paulo, SP/Brasil.

lubogus@uol.com.brLe

\section{António Miguel Lopes de Sousa}

Ministério da Cultura, Instituto do Patrimônio Histórico e Artístico Nacional. Brasília, DF/Brasil. sousa.miguel@uol.com.br

\section{Referências}

BAUMAN, Z. (2001). Modernidade líquida. Rio de Janeiro, Jorge Zahar.

BÓGUS, L. M. M. e PASTERNAK, S. (2012). "São Paulo, o espaço da desigualdade". In: BAPTISTA, D. T. e GAGLIARDI, C. (orgs.). Intervenções em Centros Históricos, Brasil e Itália em discussão. São Paulo, Educ.

BONDUKI, N. (1982). Origens do problema da habitação popular em São Paulo, 1886-1918. Espaço \& Debates. São Paulo, n. 5, pp. 81-111.

CALVINO, I. (2003). As cidades invisíveis. São Paulo, Folha de S.Paulo.

CANCLINI, N. G. (2002). Culturas híbridas: estratégias para entrar e sair da modernidade. São Paulo, Edusp.

CARDOSO, L. A. F. (1991). Entre vilas e avenidas: habitação operária em Salvador na Primeira República. Dissertação de Mestrado. Salvador, Universidade Federal da Bahia.

FORTUNA, C. (1995). Os centros das nossas cidades: entre a revitalização e a decadência. Oficina do CES. Coimbra, n. 65.

FOUCAULT, M. (2009). "Outros espaços". In: MOTTA, M. B. de (org.). Estética: literatura e pintura, música e cinema / Ditos e escritos III. Rio de Janeiro, Forense Universitária.

GIDDENS, A. (2002). Modernidade e identidade. Rio de Janeiro, Jorge Zahar.

GUILLAUME, M. (2003). A política do património. Porto, Campo das Letras. 
HEIDEGGER, M. (1951). Construir, habitar, pensar. Conferência da "Segunda Reunião de Darmastad", 1951. Publicada em Vortäge und Aufsätze, G. Neske, Pfullingen, 1954. Disponível em: http:// www.prourb.fau.ufrj.br/jkos/p2/heidegger_construir,\%20habitar,\%20pensar.pdf. Acesso em: 20 dez 2014.

LEFEBVRE, H. (2001). O direito à cidade. São Paulo, Centauro.

MARICATO, E. (2002). "As ideias fora do lugar e o lugar fora das ideias: planejamento urbano no Brasil”. In: ARANTES, O. et al. A cidade do pensamento único: desmanchando consensos. Petrópolis, Vozes.

PASTERNAK, S. e BÓGUS, L. M. M. (2014). “Habitação de aluguel no Brasil e em São Paulo". In: BALTRUSIS, N. e MOURAD, L. N. (coords.). Dossiê: Habitação e aluguel social no Brasil. Caderno CRH. Salvador, v. 27, n. 71, pp. 235-254.

PEIXOTO, P. (2003). Centros históricos e sustentabilidade cultural das cidades. Colóquio "A cidade entre projetos e políticas". Faculdade de Letras da Universidade do Porto, 30 jun.

PEREIRA, L. V. (1986). Reabilitar o urbano ou como restituir a cidade à estima pública. Lisboa, LNEC.

QUEIRÓS, J. (2007). Estratégias e discursos políticos em torno da reabilitação de centros urbanos: considerações exploratórias a partir do caso do Porto. Sociologia, Problemas e Práticas, n. 55, pp. 91-116.

SANT'ANNA, M. A. (2003). Recuperação do Centro Histórico de Salvador: Origens, Sentidos e Resultados. RUA - Revista de Urbanismo e Arquitetura. Universidade Federal da Bahia, Programa de Pós-Graduação em Arquitetura e Urbanismo, n. 8, pp. 44-59.

SMITH, N. (2006). “A gentrificação generalizada: de uma anomalia local à "regeneração" urbana como estratégia urbana global”. In: BIDOU-ZACHARIASEN, C. (coord.). De volta à cidade. Dos processos de gentrificação às políticas de "revitalização" dos centros urbanos. São Paulo, Annablume.

Texto recebido em 14/jan/2016

Texto aprovado em 31/mar/2016 
